\title{
Salt of the earth, or just salt?
}

\author{
Jay K. Bhama, MD
}

\author{
From the Section of Adult Cardiac Surgery, Department of Surgery, Carver College of Medicine, and University \\ of Iowa Health Care, Iowa City, Iowa. \\ Disclosures: Author has nothing to disclose with regard to commercial support. \\ Received for publication July 11, 2018; accepted for publication July 13, 2018; available ahead of print Aug 31, \\ 2018. \\ Address for reprints: Jay K. Bhama, MD, Section of Adult Cardiac Surgery, Department of Surgery, Carver \\ College of Medicine, University of Iowa Health Care, 200 Hawkins Dr, SE500 GH, Iowa City, IA 52246 \\ (E-mail: jay-bhama@uiowa.edu). \\ J Thorac Cardiovasc Surg 2019;157:626-7 \\ $0022-5223 / \$ 36.00$ \\ Copyright $(2018$ by The American Association for Thoracic Surgery \\ https://doi.org/10.1016/j.jtcvs.2018.07.036
}

\begin{abstract}
"Salt of the earth," one of the most popular and also enigmatic phrases from the Bible, is commonly used to signify the great worth and reliability of something. The many qualities of salt contribute both to the mystery surrounding its mention in Matthew 5:13 and to its longstanding historic value as a global commodity. When it comes to medicine, salt has also played a long-standing and historic role. ${ }^{1}$ It has been an essential part of medicine for thousands of years. Dating back to Egyptian medicine, Imhotep (2600 BCE) recommended salt for the treatment of an infected chest wound. The ancient Greeks, from Hippocrates (460 BCE) to Galen (200 CE), made frequent use of salt as an expectorant, emetic, and inhalation agent. Salt continued to play an important role in medicine through the Middle Ages (11th-13th centuries $\mathrm{CE}$ ), through the Renaissance (14th-17th centuries CE), and into modern history, where it is now, because of its physiologic likeness to human plasma when in solution, an inescapable modality in the treatment of nearly every patient who enters a hospital.

In this issue of the Journal, Riberio and colleagues ${ }^{2}$ from Toronto report on experimental research investigating the potential positive effects of hypertonic saline solution on cardiac allograft dysfunction. In a porcine model of cardiac transplantation, Riberio and colleagues ${ }^{2}$ demonstrate that advance treatment of the recipient with hypertonic saline solution infusion leads to improved weaning from bypass and left ventricular performance, as assessed by preload recruitable stroke work and endsystolic elastance. Endothelial function, as measured by coronary artery endothelial-dependent and independent relaxation, was also improved. Hypertonic saline solution also attenuated interleukin production, as well as upregulation of plasma and left ventricular tumor necrosis factor $\alpha$ expressions. This work augments previous studies by this group, also in a porcine model, demonstrating a positive effect on allograft function of
\end{abstract}

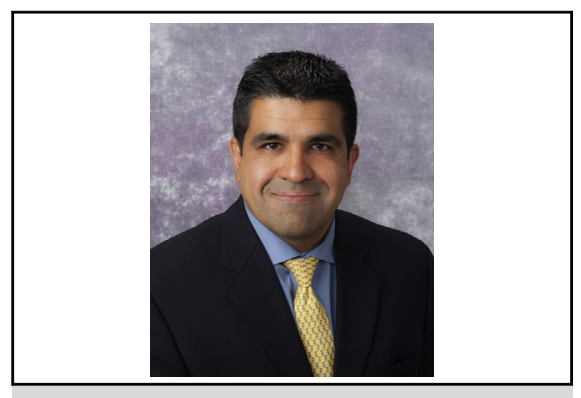

Jay K. Bhama, MD

Central Message

Hypertonic saline solution infusion appears to alleviate cardiac allograft dysfunction in a porcine model. The question remains: will this translate across species in a clinically meaningful manner?

See Editorial Commentary page 615.

hypertonic saline solution administration to the donor before organ harvest.

The Toronto group, led by Dr Rao, are to be commended for their pioneering efforts in experimental research in the area of cardiac allograft protection. They have demonstrated a tremendous commitment to experimental research, an area of cardiac surgery research that is becoming increasingly challenging and difficult to perform. Cardiac transplantation remains the criterion standard treatment for end-stage heart disease; however, donor availability remains a key challenge to its ability to meet our community's current burden of heart failure. Because little has changed through the decades in our ability to protect and transport donor organs safely, this work represents a beacon of hope for patients and providers alike. The concept that a simple infusion of concentrated salt solution given to either the donor or the recipient (or maybe even to both) might allow for extended cold ischemia and longer transport times is an extremely attractive and enticing therapeutic option. That salt's simplicity as a compound should not overshadow its tremendous potential for affecting human physiology is evidenced not only by this study but also by the omnipresent role that salt has had in the history of human medicine.

A major challenge for the Toronto group will be translating these rather promising results from an animal model to the bedside, in the form of a human clinical trial. Such 
studies will be imperative to achieving an understanding of how the science translates across species and to determining whether the concept of hypertonic saline solution for allograft protection is truly "salt of the earth"-or just salt.

\section{References}

1. Cirillo M, Capasso G, Di Leo VA, De Santo NG. A history of salt. Am J Nephrol. 1994; 14:426-31.

2. Ribeiro RV, Badiwala MV, Ramzy D, Tumiati LC, Rao V. Recipient hypertonic saline infusion prevents cardiac allograft dysfunction. J Thorac Cardiovasc Surg. 2019;157:615-25.e1 